\section{Avoidance learning in the golden hamster: The effect of CS-US interval*}

\author{
FREDERICK A. HUSSEY† \\ University of Maine, Portland, Me. 04103
}

The present study was concerned with the influence of the interstimulus interval (ISI) on shuttlebox avoidance learning in the male golden hamster. Five groups, with $10 \mathrm{Ss}$ per group, learned a barrier-jumping response under a delayed conditioning procedure. The results show that the ISI $(2,4,6,8$, and $10 \mathrm{sec})$ was positively related to the number of avoidance responses made during 100 trials. Furthermore, the number of trials to four consecutive avoidance responses was inversely related to the ISI. Mean avoidance latencies were a direct function of ISI length. ISIs of 8 and $10 \mathrm{sec}$ yielded superior results on all measures. As compared to the rat, the hamster appears to be inferior in terms of both the rate of acquisition and the final level of avoidance responding.

Use of the golden hamster (Cricetus auratus) in investigations of classical psychological phenomena has been extremely limited. Bowland \& Waters (1955) found that the performance of the hamster was comparable to that of the rat on maze learning. Pearl (1963) compared hooded and albino rats, guinea pigs, and hamsters in terms of rate of avoidance responding in a barpress situation. At the end of the experiment, the guinea pigs were well trained in avoidance behavior, the hamsters were moderately trained, and the rats failed to show an appreciable amount of avoidance learning.

The intent of the present study was to expand upon the existing knowledge concerning avoidance conditioning in the golden hamster. The purpose was to determine if the golden hamster could learn a shuttlebox avoidance response and to determine the efficacy of various CS-US intervals on learning. Based on comparable research performed with rats (Low \& Low, 1962), it was hypothesized that the rate of acquisition of avoidance responding, as evidenced by number of trials to reach a criterion of four consecutive avoidance responses, would be related inversely to CS-US interval. It was also hypothesized that latency of avoidance responding would be positively related to CS-US interval.

\section{SUBJECTS}

Fifty male golden hamsters between 60 and 80 days of age were obtained from Albino Farms, Red Bank, New Jersey. The Ss were reared in individual laboratory cages measuring $10 \mathrm{in.}$ long, $7 \mathrm{in}$. wide, and $7 \frac{1}{2} \mathrm{in}$. deep. Purina Lab Chow and water were available ad lib. For 20 days prior

*This study is based on a thesis submitted to the Graduate School of the University of Maine in partial fulfillment of the requirements for the MA degree. The author wishes to gratefully acknowledge the contribution of Roger B. Frey in the conduct of this research.

tReprints may be obtained from F. A. Hussey, The Heller School, Brandeis University, Waltham, Mass. 02154. to and during testing, the Ss were maintained under a 12-h day-night cycle (lights on from 7 a.m. to 7 p.m.). APPARATUS

The apparatus consisted of a shuttlebox, 16 in. long, 5 in. wide, and 7-5/16 in. high, with a grid floor of $1 / 8$-in. stainless steel rods spaced $3 / 8$ in. on center. The sides of the box were of $1 / 4$-in. Plexiglas and the ends

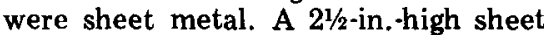
metal barrier divided the shuttle compartment into two 8-in.-long sections. A 4-in. 4-ohm loudspeaker was mounted in the center of a hinged plywood cover. The ends, barrier, and cover were painted flat black.

The two photocells of a Hunter Model 335-S photo relay were mounted in a wooden frame on the outside of the front panel of the box. The photocells were positioned $3-5 / 16$ in. above the grid and $7 / 8$ in. on either side of the barrier. A $110-\mathrm{V}$ 7-W clear bulb, located centrally $7 \frac{1}{2}$ in. behind the apparatus, served as the light source for the photocells. The photocell circuitry was so arranged that an animal had to go completely over the barrier in order to terminate the shock.

The CS was a $10-\mathrm{Hz}$ tone which was made discontinuous by a Heathkit electronic switch, Model S-3, with the rate control set at $1,500 \mathrm{~Hz}$. The tone was amplified so that the intensity was $80 \mathrm{~dB}$, measured at the grid floor. The US, which was transmitted to the grid through a Lehigh Valley shock scanner, was a $0.75-\mathrm{mA}$ shock from an Applegate constant-current dc shock generator. The shock scanner started simultaneously with the onset of the CS. Duration of the interstimulus and intertrial intervals was controlled by two Hunter timers, Model 111B.

\section{PROCEDURE}

The animals were assigned randomly to one of five groups, $10 \mathrm{Ss}$ per group. The groups were designated by the duration of the interstimulus intervals used, 2, 4, 6, 8, and 10 sec. Each $\mathrm{S}$ was given 10 successive test trials (one session) each day for 10 days. When all groups had reached an a priori criterion of 100 trials, testing was continued for those groups that were still improving in avoidance learning. Consequently, the 4-sec group was given a total of 110 trials; the $6-\mathrm{sec}$ group, 120 trials; and the 8- and 10-sec groups, 150 trials. Each group was tested daily during one of five test periods that started at approximately 9:30 a.m., 11:00 a.m., 2:30 p.m., and 8:00 p.m. The order of testing the groups was randomized, with the restriction that during the first 10 days each group would be tested twice in each test period.

On the first test day, each $S$ received a 60 -sec acclimation period, and on succeeding days a 45-sec acclimation period. The CS was presented at the end of the acclimation period, followed by the onset of the US at the appropriate interstimulus interval (ISI). When $\mathbf{S}$ crossed the barrier, the CS and US werre terminated simultaneously and the next 30 -sec ITI was started. If $S$ crossed the barrier during the ITI, the ITI was reset.

The Ss were never picked up by hand, but were transported to and from their home cages in a 1-lb coffee can. Usually the animals readily entered the can when it was placed in front of them. Sometimes, however, gentle prodding from behind facilitated their entry.

\section{RESULTS}

An analysis of variance on the number of avoidance responses during the first 100 trials (or 10 sessions) showed that there was a significant difference between groups ( $F=12.39$, df $=4 / 45, p<.01$ ), between sessions $(F=12.20, \mathrm{df}=9 / 405, p<.01)$, and $a$ significant interaction of Groups by Sessions $(F=4.08, \quad \mathrm{df}=36 / 405$, $\mathrm{p}<.01$ ). Duncan's new multiple range test on mean number of avoidance responses per session (Table 1) indicated that the 8- and 10-sec groups made significantly more avoidance responses than all other groups, but not different from each other. The 6-sec group emitted significantly more avoidance responses than the 2 - and 4-sec groups, with the latter not significantly different from each other.

Table 1

Mean Number of Avoidance Responses Per Session

\begin{tabular}{cc}
\hline $\begin{array}{c}\text { CS-US Interval } \\
\text { (Seconds) }\end{array}$ & $\begin{array}{r}\text { Mean Number } \\
\text { of Responses }\end{array}$ \\
\hline 2 & 3.0 \\
4 & 9.0 \\
6 & 23.0 \\
8 & 37.0 \\
10 & 35.0 \\
\hline
\end{tabular}




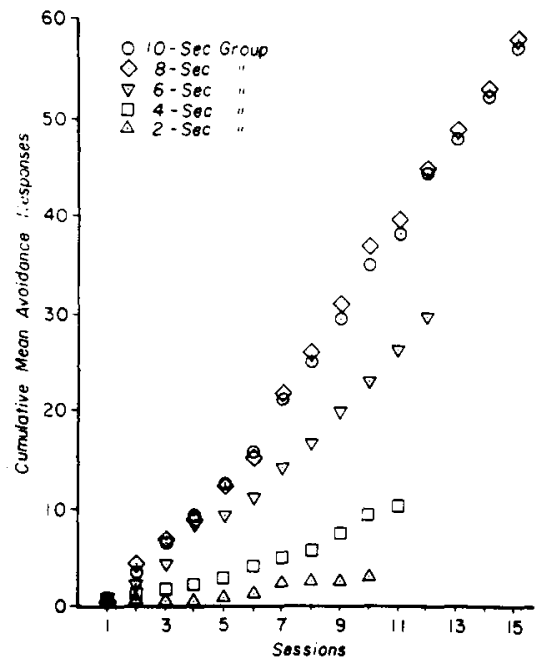

Fig. 1. Cumulative mean avoidance responses over sessions.

Figure 1 shows the difference in the acquisition of the avoidance behavior and the relative position of the groups in terms of cumulative mean avoidance responses. It can be seen that the 8 and 10-sec groups were practically identical and superior to the other groups. The significant Groups by Sessions interaction is also apparent from Fig. 1.

Mean avoidance and mean escape latencies are presented in Fig. 2. Although the avoidance latencies are a direct function of interval length, the escape latencies show no systematic or large change as a function of the CS-US interval length.

In addition to mean avoidance responses and latency measures, there are other indices of avoidance performance that are typically used. Most common is the number of trials to the first avoidance response. More stringent criteria, such as number of trials to two, three, or four consecutive avoidance responses, are also used. Figure 3 shows the median number of trials to one, two, three, and four consecutive avoidance responses for each CS-US interval group. An $\mathrm{S}$ not meeting the criterion was omitted from the data, and the number of Ss contributing to each data point are indicated in parentheses. It is evident that, as the criterion is made more stringent, there are fewer animals in each group that meet the criterion. However, with long CS-US intervals, more animals meet each of the criterion levels.

\section{DISCUSSION}

One of the aims of the present study was to determine whether the golden hamster could learn the avoidance response in a shuttlebox situation. That the hamster can learn such a response has been demonstrated adequately by this study. It is interesting, however, to compare the performance of hamsters to that of rats in a comparable situation. When compared with the results of Low \& Low (1962), who employed a similar methodology with rats in a shuttlebox situation, it is apparent that the hamster is somewhat inferior to the white rat in avoidance learning. This is evidenced by the fact that, to obtain the same level of avoidance responding as that yielded by the white rat using a CS-US interval of $2 \mathrm{sec}$, it would be necessary to use an interval of approximately $7 \mathrm{sec}$ with the hamster. It should be pointed out, however, that the replacement of poorly performing $\mathrm{Ss}$ in the Low \& Low (1962) study makes such a comparison highly tenable.

It was found in the present study that trials to first avoidance response were related inversely to CS-US interval, whereas no differences were found on this measure with rats (Low \& Low, 1962). Seemingly, the rat does not learn the avoidance response more quickly as the CS-US interval length increases, as is true of the hamster. Again, the replacement procedure used by Low \& Low (1962) would seem to negate an exacting comparison.

The results of the present study indicate that hamsters may be inferior to rats in shuttlebox avoidance behavior. However, there is some evidence that species differences depend on the type of test situation used. Pearl (1963), using a barpress situation, reported that, after equal amounts of training, hamsters attained a moderate level of avoidance

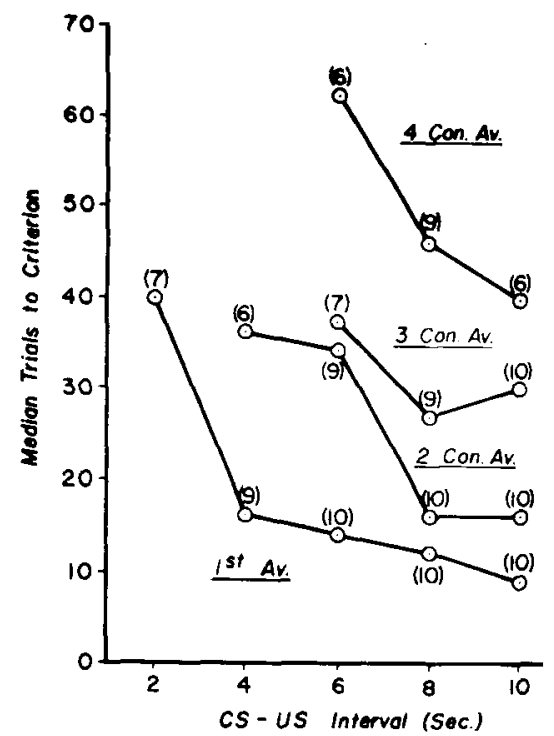

Fig. 3. Median trials to criteria of first avoidance response and to 2,3 , and 4 consecutive a voidance responses.

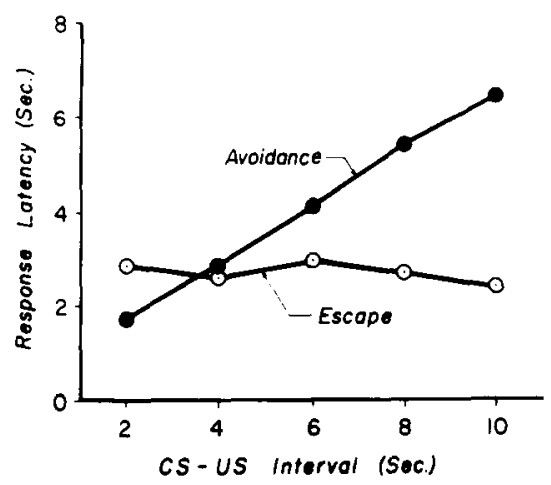

Fig. 2. Mean avoidance and escape latencies as a function of CS-US interval.

behavior, whereas rats failed to show an appreciable amount of avoidance behavior. Thus, it would appear that, when evaluating the two species in terms of relative superiority of avoidance behavior, it is necessary to consider the type of response required, as well as the results obtained.

The finding that mean avoidance latencies are a direct function of CS-US interval is in agreement with that for rats (Low \& Low, 1962) and for dogs (Brush, Brush, \& Solomon, 1955; Kamin, 1954). This result is contrary to that obtained with fish (Behrend \& Bitterman, 1964). Behrend and Bitterman employed intervals from 0.0 to $1.0 \mathrm{sec}$ and reported that avoidance latencies were related inversely to ISI length.

The findings of the present study are also similar to those of Pearl (1965), using gerbils, and Low \& Low (1962), using rats, in that the longer CS-US intervals led to better conditioning. In view of this finding, it would be desirable to know how the hamster would perform if longer intervals were used. Contrary to evidence gathered using rats (Black, 1963), it is quite possible that, in hamsters, $8-10 \mathrm{sec}$ is the lower boundary for a range of optimal CS-US intervals.

Observations made during the course of the study gave the impression that the groups were alike in the direction of increment or decrement in performance during a given session. That is, if one group improved, the others did, and vice versa. From Session 1 to Session 15, the majority of the groups alternated in direction of change. However, on Sessions 4,10 , and 15 this alternation in the direction of increment or decrement did not occur. The observed alternation of direction of change, with the exceptions mentioned, seemed to indicate that there might be a $48 \cdot \mathrm{h}$ behavioral cycle 
in the male hamster. However, a one-sample runs test (Siegel, 1956) on the order of direction did not indicate a pattern different from that expected by chance.

In the present study, $S$ was not punished for intertrial crossings of the barrier. Consequently, the frequency of intertrial responding was generally high, which in turn resulted in an increase in length of the ITI and a concurrent increase in running time. Since it is difficult to assess the consequence of variable ITIs, it would seem preferable to eliminate ITRs. One procedure for the elimination of ITRs is the punishment of the organism by shocking it after crossing the barrier. However, it would seem that punishing $S$ for behavior similar to the desired response might lead to a suppression of the desired behavior. A possible solution to this problem would be to punish the organism for ITRs only after the avoidance response has been partially acquired.

The present study demonstrated that the golden hamster can learn a shuttlebox avoidance and that the intervals used do lead to different results. It is felt that further research on avoidance conditioning in the hamster should include the evaluation of longer CS-US intervals than those employed in the present study. Furthermore, it would seem worthwhile to investigate the possibility of a 48 -h behavioral cycle in the hamster.

\section{REFERENCES}

BEHREND, E. R., \& BITTERM AN, M. E. Avoidance conditioning in the fish: Further studies of the CS-US interval. American Journal of Psychology, 1964, 77, 15-28.

BLACK, A. H. The effects of CS-US interval on avoidance conditioning in the rat Canadian Journal of Psychology, 1963, 17, 174-182.

BOWLAND, J. A., \& WATERS, R. H. Maze learning in the golden hamster and the albino rat. Psychological Reports, 1955. $1,437-440$.

BRUSH, F. R., BRUSH, E. S., \& SOLOMON R. L. Traumatic avoidance learning: The effects of CS-US interval with delayed conditioning procedure Journal of Comparative \& Physiological Psychology, 1955, 48, 283-293.

KAMIN, L. J. Traumatic avoidance learning: The effects of CS-US interval with a trace conditioning procedure. Journal of Comparative \& Physiological Psychology, $1954,47,65-72$.

LOW. L. A., \& LOW, H. I, Effects of CS-US interval length upon avoidance responding. Journal of Comparative \& Physiological Psychology, 1962, 55, 1059-1061.

PE ARL, J. Avoidance learning in rodents: A comparative study. Psychological Reports, 1963, 12, 139-145.

PEARL, J. Effects of CS-US interval on avoidance performance of gerbils. Paper presented at the meeting of the Eastern Psychological Association, Atlantic City. 1965.

SIEGEL, S. Nonparametric statistics. New York: McGraw-Hill, 1956.

\section{Effects of methamphetamine hydrochloride on imprinting in White Leghorn chicks*}

\author{
D. W. RAJECKI and SUSAN SAEGERT \\ University of Michigan, Ann Arbor, Mich. 48104
}

The state of arousal in young precocial birds is a determinant of the strength of the social bond formed during an imprinting opportunity. Imprinting is inhibited in Ss under the influence of sodium pentobarbital, a tranquilizer. Conversely, birds aroused through exposure to additional external stimulation or the influence of the stimulant racemic amphetamine sulfate show enhanced social responses. The current study extends the work on amphetamines by employing methamphetamine hydrochloride as a stimulant. It was found that, relative to saline controls, animals under the influence of the excitant yielded reliably stronger indices of imprinting.

Experimentally induced levels of arousal have been found to be a strong influence on the process of imprinting. It has been shown that interference with CNS activity through the administration of a tranquilizer produces lowered imprinting scores. Bradford \& Macdonald (1969) found that sodium pentobarbital administered prior to training sessions reduced improvement in imprinting

* This research was supported by NSF Grant No. GS3119 to Robert B. Zajonc. over trials in proportion to the size of the dose. The highest dosage employed $(10 \mathrm{mg} / \mathrm{kg}$ ) prevented any improvement. Similarly, Macdonald (1968) showed that birds maintained on a schedule of pentobarbital injections could be imprinted past their normal critical period. Macdonald interprets these results as demonstrating that the drug prevented the birds from imprinting on the general environment.

On the other hand, arousal has been increased by the mechanical introduction of additional stimulation at a point when the $\mathrm{S}$ is in a position to observe the imprinting target. The sound of a wooden clapper (Pitz \& Ross, 1961) or the administration of electrical shock (Kovach \& Hess, 1963), applied to Ss when in proximity to an imprinting object, produced greater imprinting scores relative to control $\mathrm{Ss}$ that did not receive like stimulation. In a study in which only 7 of 18 bobwhite quail responded socially to a live sparrow hawk, one $S$ demonstrated strong approach tendencies after it had been attacked and dropped to the floor by the imprinting object (Melvin, Cloar, \& Massingill, 1967).

Kovach (1964) suggests that a mediator of such enhanced acquisition is autonomic arousal. He shows that the adrenergic stimulant, racemic amphetamine sulfate (as well as ephedrine and epinephrine), improved following in Vantress Broiler chicks up to $18 \mathrm{~h}$ of age. Kovach goes on to remark, however, that induced or maturationally produced levels of CNS excitement may be more critical to the behavior than sympathetic nervous activity. This may be the case, since amphetamines operate on the CNS and have been found to facilitate the physiological correlates of alertness, the monitoring of cues, and motor performances (for a review see Cole, 1967).

In this study the examination of the influence of amphetamines on imprinting is extended. A different a mphetamine compound, methamphetamine hydrochloride, was employed, as was a different variety of chick.

\section{SUBJECTS}

Ss were two groups of 12 Dekalb hybrid (White Leghorn variety) chicks hatched and housed socially in groups of 4 to 20 . All birds were tested at 12 to $24 \mathrm{~h}$ of age.

\section{APPARATUS}

Testing was done in an uncovered open-ended runway $7 \mathrm{in}$. wide and deep and $5 \mathrm{ft}$ long. The interior walls of the runway were painted flat black, and the floor was lined with disposable absorbent paper. Butted against each end of the runway was the wire mesh wall of a $7 \times 7 \times 9.75$ in. Holtege metal cage with flat-black interior walls. One cage was empty and the other contained the imprinting target: a motor-powered $3 \times 5$ in. canary-yellow card that spun at $60 \mathrm{rpm}$ on a horizontal axis. The cages were illuminated by shaded $200 \cdot \mathrm{W}$ bulbs suspended overhead; the runway was illuminated by fluorescent ceiling lamps.

\section{PROCEDURE}

Forty minutes prior to testing, Ss in the experimental group (D) were 